\title{
From Times Square to Eyre Square: Hackathons as Authentic Learning for Information Systems Students
}

\section{Mairéad Hogan}

Business Information Systems Group, JE Cairnes School of Business and Economics, National University of Ireland Galway, Ireland.

\begin{abstract}
In order to ensure students meet the learning outcomes for a module in user experience design, an authentic learning approach was used to design a User Experience (UX) Hackathon, called Empathy Jam. UX hackathons are short events where participants work in groups on a challenge, using user-centred design techniques. The learning from the hackathon comes through the process of taking part, as well as collaborative learning from their team members. An important feature of Empathy Jam is collaboration with industry partners who act as mentors to guide the participants through the process. Assessment of learning was done through the use of video and reflective journals. The groups created a video record of their day, demonstrating their engagement and participation as a group, as well as the group learnings. Individual learnings were assessed through reflective journals. Feedback on the event was obtained through the journals, vox pops on the day, a feedback survey and feedback from the mentors.
\end{abstract}

Keywords: hackathon; Empathy Jam; authentic learning; user experience design. 


\section{Introduction}

As part of a review of a Master's level module in user experience design (UXD), Biggs' (1999) constructive alignment approach was used, whereby teaching and learning activities, learning outcomes and assessment techniques are aligned to ensure students meet the learning outcomes through appropriate teaching and learning activities. Assessment techniques can be used both as an aid to learning and to assess whether learning has taken place. This paper will focus on the re-design of the continuous assessment (CA) component of the module.

The previous CA consisted of a group assignment whereby students completed a series of development tasks while engaging with typical users to inform each stage of the process. While some groups fully engaged and used the output from each stage to inform the next, not all did. It was apparent that, similar to groups identified by De Hei, Strijbos, Sjoer, and Admiraal (2014), some groups simply divided the tasks and attempted to fit the results together to produce the final submission. As a result, students were not achieving all the learning outcomes for the module. To rectify this, it was decided to use assessment for learning (Nicol \& Macfarlane- Dick, 2006) rather than assessment of learning.

\section{Learning Approaches}

\subsection{Authentic Learning}

A common approach to ensuring students develop necessary employment skills is authentic learning (Black, 2019). Authentic learning requires an environment with real-world challenges where students use their developing skills and knowledge to solve problems. This often takes the form of work placement or internships. For this module, it was decided that a simulated approach to real-world challenges could be used to provide authentic learning.

According to Wilson (2017), authentic learning requires: authentic, complex and rich problems; an environment that resembles a real-world situation; encouragement of the learner to take ownership of the process; provision of opportunities for realistic interactions; opportunity for reflection on the part of the learner; guidance and facilitation by the instructor. Mejías and Monereo (2017) state authentic learning should motivate students to "become actively involved in the tasks and connect them to the world outside the classroom". They stress authenticity and reality are not necessarily the same thing. Authenticity refers to the extent to which the tasks presented to students are realistic, relevant and socialising.

As most work environments involve a level of collaboration with co-workers, an authentic learning experience should reflect this. Knapper (2008) also suggests collaborative team learning can improve individual student learning. In addition to contributing to an authentic learning experience, collaboration can enhance individual learning (De Hei et al., 2014). Laal and Ghodsi (2012) identify a number of social, psychological and academic benefits to 
collaborative learning, including social support for learning, increased self-esteem, improved critical thinking skills, improved motivation and ownership of the learning process.

\subsection{Hackathons}

The term Hackathon is a combination of hacking, defined as "a usually creatively improvised solution to a computer hardware or programming problem or limitation" (Merriam Webster, 2020) and marathon, which suggests an endurance event. The aim of a hackathon is to bring together people from a variety of backgrounds who will work on a problem for a specified period of time (Calco \& Veeck, 2015). They will generally produce some form of prototype to visualize a potential solution to the problem. Coding or technical hackathons are commonly held, but the concept has extended to other areas such as marketing (Calco \& Veeck, 2015) and science (Groen \& Calderhead, 2015).

According to Komssi, Pichlis, Raatikainen, Kindström, and Järvinen (2015), all hackathons have certain key characteristics: they begin with generation of ideas and team building; they are time-bound, with teams producing a concrete vision of their idea; teams present their idea to the audience; some ideas are judged worthy of further development; participants experience personal development. Some of the key benefits of hackathons to participants are: enhancement of skills, creativity and critical thinking; personal development; innovation; and networking (Calco \& Veeck, 2015; Groen \& Calderhead, 2015; Komssi et al., 2015).

\subsection{Hackathons in Education}

As hackathons enhance participant skills and knowledge by allowing them to actively engage with a problem, there is potential to use them as a learning tool for students. Gama, Alencar, Calegario, Neves, and Alessio (2018) state hackathons are a useful tool for experiential learning as they provide the practical, contextual and social aspects required. They are also useful as a mechanism for peer learning. Kienzler and Fontanesi (2016) recognised the hackathon as an approach that, through inquiry, facilitates collaborative learning. Through the use of a one-day classroom hackathon, they applied an Inquiry Based Learning (IBL) approach to facilitate Global Health students gaining knowledge through independent inquiry and the development of transferrable skills. Similarly, Gama et al. (2018) used a 24-hour classroom hackathon for an Internet of Things class while Page, Sweeney, Buruce, and Baxter (2016) held a 5-day hackathon for Product Design and Digital Interaction education.

When using hackathons for educational purposes, Page et al. (2016) suggest: using icebreakers for the teams; providing teams with sufficient wall space for display and collective discussion; providing guidelines on team formation; discouraging the use of technology at the early stages; provision of guidelines to assess progress; provision of similar facilities to all teams; and provision of a relevant and future-oriented conclusion. 


\section{Empathy Jam: From New York to Galway}

Empathy Jam (https://www.empathyjam.com) originated in New York in 2016. Their tagline is "Empathize, collaborate, and design a better New York". It is a day long user research and design hackathon, similar to a coding hackathon but focusing on the User Experience (UX) process, rather than technical development. Participants perform user research with people in the locality, use the information to create design solutions and then test these solutions.

In November 2018, the inaugural Empathy Jam Galway took place just off Eyre Square, in the city centre. Mentors, judges and speakers, all well-versed in the skills needed for UX design, came from industry and academia in order to give a broad perspective to participants. Prizes, refreshments and lunch were sponsored by local organisations. External to the MSc class, the event was promoted through mailing lists, a press release, Twitter, LinkedIn, the University calendar and on screens in the University. In total, there were 40 participants, 25 from the MSc class and 15 external participants who came from industry, a research background, or just thought "it would be a fun thing to do".

Prior to the event, the participants were given helpful links to similar events and to UX sites and stories. Twitter, Facebook and LinkedIn were all used to engage the participants. The challenges were presented on the day, but hints were tweeted in advance. The challenges the participants addressed were based on issues that affect the citizens of Galway.

The day provided an authentic learning experience by following an accelerated approach to user research and design. The guidance by Page et al. (2016) on using hackathons for education purposes was followed. Additionally, talks were given by experts on empathy and user research prior to the initial exploratory and user research sessions. A talk on low-fidelity prototyping was given before the next phase, which required participants to consolidate the results of their user research, create paper prototypes and test them with potential users.

\section{Empathy Jam Galway}

\subsection{Background}

The students who participated in this UX hackathon were studying for an MSc in Information Systems management. The cohort involved in this exercise had varied backgrounds. Some progressed directly from a variety of undergraduate programmes (e.g. Arts, Business, Engineering) while others were mature students who had already spent a number of years working in a technical role. None had a background in UXD.

The skills taught in the module are those of user-centred design. Students need to understand the importance of:

- User research as a way of understanding what the user needs. 
- Design skills to determine the best approach to create the user experience.

- Evaluation skills so they can hone and perfect the design.

Empathy, which facilitates understanding the user, is a key requirement to building an effective user experience. However, research (Lunström, Åberg, \& Blomkvist, 2015) has found people, particularly males, working in the technology field tend to have lower empathy. The demographics in the MSc class described in this study has always been more skewed towards males with a technical background. They tend to be strong students technically but often lacking in the softer skills needed to design an effective user experience.

As part of the re-design of this module, it was decided the assignment should provide the students with an authentic learning experience to enable them to fully understand the importance of user involvement. Empathy Jam Galway was considered an ideal approach to facilitate this. The day was a collaborative effort, including mentors and judges from academia and industry, thus exposing students to experience from both. Industry involvement was considered an important feature of the authentic learning experience for students.

\subsection{The Process}

On the day itself, participants arrived at 9am for registration/refreshments/networking. They formed groups of 5 . The participants were given templates for empathy maps and user flow diagrams. They were also given tips on how to conduct user research effectively. Guerrilla user interviews, which are short and quick, were encouraged. The challenges were presented, and the day began in earnest. In order to maximise the engagement of the public, locally relevant challenges were chosen:

- How might technology ease the issue of traffic congestion in Galway City?

- How might elderly people engage with technology to prevent loneliness and social exclusion?

The teams were encouraged to explore their chosen challenge with the guidance of mentors, who helped the teams to understand the importance of planning and research. Mentors were particularly good at pulling back teams who just wanted to start designing, by helping them to tackle the challenge in a holistic way. The teams explored their chosen problem and planned how best to engage potential users and to gather data relating to the problem. They then went out into the city and conducted user research.

The teams, many of whom were nervous about the prospect of approaching strangers in the street, arrived back from the sessions excited and enthusiastic. They now seemed to understand the importance of engaging with users. Their preconceptions were challenged. Suddenly they were no longer dealing with a technical problem but a human one. 


\subsection{Prototyping and testing}

After lunch, participants were given a talk on prototyping. The emphasis was on low-fidelity approaches. They then spent time synthesising their research findings and creating prototypes with the variety of materials (paper, pencils, sticky notes etc.) provided to them. The mentors were again on hand to offer help and advice. The next step was testing the prototypes. With help from the mentors, the participants planned how best to conduct testing. Quick and dirty approaches, which are suitable for low fidelity prototypes, were encouraged. The participants again had a good response from people on the street. Once they synthesised the feedback, they updated the prototypes and presented on their experience.

\subsection{Presentations and judgement time}

Each team had 3 minutes to present their project. It was interesting to see how the teams progressed. Some had false starts and some pivoted on their ideas. The key was each team was open to change and feedback, which is required to create an empathy-driven solution. Prizes were awarded for the most civic minded solution, the most innovative solution, and best user research. A summary of the day can be seen at https://gopro.com/v/KRRedn7kDa19D. It was obvious teams now recognised the importance of user involvement and empathy in the design process, thus fulfilling the main aim of the re-designed assignment. Their confidence was also enhanced in the use of the process.

\subsection{The assignment}

Previous assignments for this module were in a traditional written format. As part of the module review, it was decided to explore alternative approaches, with a video record of the day being chosen as the most appropriate format. Hawley and Allen (2018) state the main benefits of video creation for assignments include learning digital and communication skills and increased learning on the subject matter. Students also enjoy the process and it motivates them to learn. However, it is important to ensure the assignment aligns with the learning outcomes for the module. It is also necessary to provide students with support for the process as it is a relatively innovative approach.

The groups were asked to produce a 7-minute video to demonstrate what they did, and what they learned, on the day. The videos were then posted on a YouTube channel (https://www.youtube.com/playlist?list=PLc5frCfH2v_DU62LFYZZIHFv12r_ieQD-) for assessment. For inspiration, they were pointed to some vlogs created by attendees of hackathons. They were provided with advice on copyright, as well as pointers to potential tools. The university has a MakerSpace resource where students can borrow equipment such as drones, gimbals and cameras. They also provide training sessions on mobile phone video production. Students were also required to submit a 1-page reflective journal detailing what went well, what could be improved, and what they felt were their main personal learnings. 
The videos demonstrated the enthusiasm and engagement of the students. From the videos, reflective journals and discussions, it was clear they had met the learning outcomes. Several students asked could more events of this nature be organised, as it really helped them to understand the importance of user involvement and how user involvement improves design. Additional feedback was also obtained through vox pops on the day, a feedback survey and feedback from mentors. The feedback was predominantly positive, but some changes were made going forward. The expert talks at the beginning of the sessions were streamlined and some additional tools were suggested to participants for user research and testing.

\section{Learnings from Empathy Jam Galway}

Empathy Jam Galway was very successful, with learnings for students and the lecturer. Students learned vital skills for user experience design and developed an understanding of the importance of empathy and user involvement for product development. Additionally, they learned valuable communication and teamworking skills. The lecturer learned the importance of adding realism to assignments, in order to ensure learning outcomes are met.

The event was a success for a number of reasons, not least because of the involvement of industry partners who provided mentors with real world experience. Students felt this added additional realism. The mentors were also essential in guiding participants and ensuring they approached the challenges in an appropriately user-centred manner. The careful planning of the day, following an authentic learning approach, was important to ensure a well-managed event that allowed the participants to complete the challenge in the timeframe allowed.

For events of this nature, the author recommends: careful structuring of the event, using an authentic learning approach; industry partnership; mentors who can keep the process on track; and provision of resources, such as talks, tools (e.g. empathy maps) and materials for brainstorming and design. It is also important the challenges are relevant to the local community in order to ensure willingness on the part of the public to co-operate with participants. Engagement via social media in advance of the event also helped generate excitement and enthusiasm amongst the participants. While the video assessment was very successful, it is essential to provide adequate guidance and tools to allow the students to complete the videos successfully. Requiring a reflective journal is important to give the students an opportunity for personal reflection to consolidate their learnings. Overall, the use of a UX Hackathon for a class of this nature was very successful. It could also be easily adapted to other subject areas, such as coding, market research and product design.

\section{References}

Biggs, J. (1999). What the student does: Teaching for enhanced learning. Higher Education Research \& Development, 18(1), 57-75. 
Black, K. (2019). Perspectives on: Authentic learning with large student groups. Retrieved from https://charteredabs.org/publications/perspectives-on-authentic-learning-withlarge-student-groups/

Calco, M., \& Veeck, A. (2015). The markathon: Adapting the hackathon model for an introductory marketing class project. Marketing Education Review, 25(1), 33-38. doi:10.1080/10528008.2015.999600.

De Hei, M. S. A., Strijbos, J.-W., Sjoer, E., \& Admiraal, W. (2014). Collaborative learning in higher education: Lecturers' practices and beliefs. Research Papers in Education, 30(2), 232-247. doi:10.1080/02671522.2014.908407.

Gama, K., Alencar, B., Calegario, F., Neves, A., \& Alessio, P. (2018). A hackathon methodology for undergraduate course projects. Paper presented at the IEEE Frontiers in Education Conference, San Jose, CA, USA.

Groen, D., \& Calderhead, B. (2015). Science hackathons for developing interdisciplinary research and collaborations. eLife, 4, e09944. doi:10.7554/eLife.09944.

Hawley, R., \& Allen, C. (2018). Student-generated video creation for assessment: Can it transform assessment within higher education? International Journal for Transformative Research, 5(1), 1-11. doi:10.2478/ijtr-2018-0001.

Kienzler, H., \& Fontanesi, C. (2016). Learning through inquiry: A global health hackathon. Teaching in Higher Education, 22(2), 129-142. doi:10.1080/13562517.2016.1221805.

Knapper, C. (2008). Changing teaching practice: Strategies and barriers. Paper presented at Taking Stock: Symposium on teaching and learning research in higher education, Ontario, Canada.

Komssi, M., Pichlis, D., Raatikainen, M., Kindström, K., \& Järvinen, J. (2015). What are hackathons for? IEEE Software, 32(5), 60-67.

Laal, M., \& Ghodsi, S. M. (2012). Benefits of collaborative learning. Procedia - Social and Behavioral Sciences, 31, 486-490. doi:10.1016/j.sbspro.2011.12.091.

Lunström, M., Åberg, J., \& Blomkvist, J. (2015). Perceptions of software developers' empathy with designers. Paper presented at the 2015 British HCI Conference, Lincoln, Lincolnshire, UK.

Mejías, E., \& Monereo, C. (2017). As life itself: Authentic teaching and evaluation of professional consulting competencies in a psychology course. In E. Cano \& G. Ion (Eds.), Innovative practices for higher education assessment and measurement: IGI Global.

Merriam Webster. (Ed.) (2020).

Nicol, D. J., \& Macfarlane- Dick, D. (2006). Formative assessment and self- regulated learning: A model and seven principles of good feedback practice. Studies in Higher Education, 31(2), 199-218. doi:10.1080/03075070600572090.

Page, F., Sweeney, S., Buruce, F., \& Baxter, S. (2016). The use of the "hackathon” in design education: An opportunistic exploration. Paper presented at the International Conference on Engineering and Product Design Education, Aalborg, Denmark.

Wilson, B. G. (2017). Constructivism for active, authentic learning. In B. Reiser \& J. Dempsey (Eds.), Trends in instructional design and technology (pp. 61-67). Boston, MA: Pearson. 